\title{
A INDÚSTRIA DA MODA EM CONFLITO: O PARADIGMA DO CRESCIMENTO ECONÔMICO VERSUS O PARADIGMA DA SUSTENTABILIDADE
}

\author{
Camile Serraggio Girelli ${ }^{1}$ \\ Karen Beltrame Fritz ${ }^{2}$
}

\section{RESUMO}

Com a criação do mercado fast-fashion, o consumo da indústria da moda tem crescido significativamente nas últimas décadas. Para acompanhar esse crescimento, a cadeia produtiva das matérias primas, especialmente a produção de algodão, vem sofrendo alterações. Umas das principais modificações é a industrialização da agricultura. Diante disso, cria-se um impasse entre o paradigma do crescimento econômico e o paradigma da sustentabilidade. Como alternativa para este conflito paradigmático sugere-se uma mudança sistêmica na cadeia produtiva para que possa-se garantir seu desenvolvimento em interdependência com o conjunto de seus ambientes - humano e natural - sem reduzi-los a uma finalidade econômica.

PALAVRAS-CHAVES: Cotonicultura; Crescimento Econômico; Moda; Paradigma; Sustentabilidade.

\section{THE FASHION INDUSTRY IN CONFLICT: THE PARADIGM OF ECONOMIC GROWTH VERSUS THE SUSTAINABILITY PARADIGM}

\begin{abstract}
With the creation of the fast-fashion market, the consumption of the fashion industry has grown significantly in recent decades. In order to keep up with this growth, the production chain of raw materials, especially cotton production, has been changing. One of the main modifications is the industrialization of agriculture. Given this, an impasse is created between the paradigm of economic growth and the paradigm of sustainability. As an alternative to this paradigmatic conflict it is suggested a systemic change in the productive chain so that its development can be guaranteed in interdependence with the whole of its environments (...).
\end{abstract}

KEYWORDS: Cotton Production; Economic Growth; Fashion; Paradigm; Sustainability.

\footnotetext{
${ }^{1}$ Graduada em Direito pela Universidade de Passo Fundo. Aluna erasmus da Universidade de Coimbra. Advogada. Mediadora Familiar pelo Centro de Estudos da Família e do Indivíduo. Pós-Graduada em Direito Processual Civil pela Universidade Anhanguera-Uniderp. Mestre em Direito pela Universidade de Passo Fundo. Endereço eletrônico: camilegirelli@ outlook.com. Endereço postal: Avenida Montenegro, n. 329, apto 401, CEP: 90460-160, Porto Alegre/RS.

${ }^{2}$ Professora do Mestrado em Direito (PPGDireito) e do Mestrado em Administração (PPGAdm) da Universidade de Passo Fundo (UPF). Coordenadora da Editora da Universidade de Passo Fundo. Endereço eletrônico: karenfritz@upf.br. Endereço postal: Avenida Major João Schell, n. 988, CEP 99020-020, Passo Fundo/RS.
}

Rev. de Direito, Economia e Desenvolvimento Sustentável| e-ISSN: 2526-0057| Porto Alegre | v. 4 | n. 2 | p. 1 - 16 | Jul/Dez. 


\section{CONSIDERAÇÕES INICIAIS}

O presente trabalho científico busca confrontar o paradigma do crescimento econômico e o paradigma da sustentabilidade para que se possam analisar algumas questões que giram em torno do mercado da moda ${ }^{3}$ em uma perspectiva sustentável. Para isso há que se pensar: qual o verdadeiro custo global para que uma peça de roupa, ao chegar ao consumidor final, tenha um preço justo? Ao comprar uma peça de roupa, muitas vezes, o que o consumidor leva em consideração é o preço e o aspecto estético, deixando de perceber que, para que chegasse até suas mãos, foi objeto de um ciclo de produção que é composto por seis etapas, são elas: 1) plantação e produção da fibra - produção de algodão especificamente para a análise no presente artigo; 2) design; 3) confecção da peça; 4) logística e distribuição; 5) uso e manutenção; 6) fim da vida útil e descarte.

Cada uma dessas etapas do ciclo de vida influencia o valor final do produto, uma vez que, para termos uma real noção do seu custo final há que se somar ao cálculo, de forma exemplificativa e simplória: os custos com a semente, a plantação, a irrigação, a colheita e a produção da matéria-prima que dará forma à fibra, bem como seu custo dentro da biodiversidade, depois, o transporte da fibra até a equipe que planeja e desenha a peça, a qual, uma vez idealizada, somam os custos da produção e confecção da peça, soma-se a isso a propaganda, assim como a logística e distribuição, devem ser levados em conta, ainda no mesmo cálculo, os custos com a lavagem e a manutenção pelo consumidor, bem como todos os valores que caracterizam o descarte da peça, sem esquecer, obviamente dos impactos ambientais e sociais da mesma. Se, ao final do cálculo, mesmo assim, o produto tiver um preço muito baixo, ter-se-á a certeza de que alguma das etapas do seu ciclo de vida sofreu defasagem e teve desconsiderada sua importância para a concepção do produto final.

Por não ter a pretensão de exaurir o tema, bem como para que seja possível o começo de uma abordagem mais densa, iremos analisar apenas a primeira etapa do ciclo de vida das roupas, como visto a produção de algodão, que serve de matéria prima para a confecção da peça. Além disso, iremos analisar, especificamente, o impacto da cotonicultura no meioambiente, uma vez que o algodão é a fibra natural mais utilizada pela indústria têxtil no mundo.

\footnotetext{
${ }^{3} \mathrm{Na}$ presente pesquisa, ao usar o termo 'moda' não estamos nos referindo às tendências da coleção desta ou de outra temporada, de uma ou de outra marca. Estamos nos referindo ao ciclo de vida, ao ciclo de produção de uma peça de roupa, à própria indústria da moda. Isto porque "A moda está muito mais relacionada a um conjunto de fatores, a um sistema de funcionamento social, do que especificamente às roupas, que são apenas a ponta do iceberg." POLLINI, 2007, p. 17.
}

Rev. de Direito, Economia e Desenvolvimento Sustentável| e-ISSN: 2526-0057| Porto Alegre | v. 4 | n. 2 | p. 1 - 16 | Jul/Dez. 
O método escolhido para a presente análise é o dialético, uma vez que este constrói um meio dinâmico de interpretação, buscando explicar as contradições apresentadas, eis que compreende a realidade como contraditória e em permanente transformação.

\section{A MODA ENTRE O PARADIGMA DO CRESCIMENTO ECONÔMICO E O PARADIGMA DA SUSTENTABILIDADE}

O sistema econômico mundial como vemos hoje, é um sistema em crise, isso porque, de um lado temos o consumo desenfreado em um sistema linear que se inicia na extração de matéria prima, a qual vai para produção de peças, com a consequente venda e uso, e, por fim, o descarte; mas, do outro, temos um planeta com recursos escassos e finitos. Essa equação conduz, inevitavelmente, a um colapso.

Na década de 60, a crise ambiental já vinha sendo analisada e debatida por pesquisadores e ambientalistas. A percepção de uma série de desastres e desequilíbrios dos ecossistemas levou a comunidade científica e governantes conscientes a considerarem essa questão um problema de ordem mundial. (BERLYN, 2012, p. 16)

\footnotetext{
O estado democrático regido pela moda é por um lado, a tendência ao eclipse das grades autoridades diretoras, pelo outro, a disseminação das pequenas influências, ora determinantes, ora superficiais; é tempo das influências precárias à la carte. (LIPOVETSKY, 2009, p. 321)
}

Diante desta percepção, em 1972 foi realizada na cidade de Estocolmo, na Suécia, a Conferência das Nações Unidas para o Meio Ambiente Humano, com a participação de chefes de estado e comandada pela Organização das Nações Unidas (ONU), tendo sido pioneira das conferências globais relacionadas ao meio ambiente.

Posteriormente a isso, precisamente no ano de 1987, a ONU criou a Comissão Mundial sobre o Meio Ambiente e Desenvolvimento, da qual resultou o relatório denominado "Nosso Futuro", usualmente conhecido como Relatório Brundtland. Este relatório não apenas aponta incompatibilidades entre a produção e o consumo, preocupando-se com as futuras gerações, como também cria o conceito de desenvolvimento sustentável como sendo "um processo que satisfaz as necessidades presentes, sem comprometer a capacidade das gerações futuras de suprir suas próprias necessidades" (RELATÓRIO BRUNDTLAND). 
Ocorre que esse desenvolvimento sustentável está sob grave ameaça haja vista a contínua e intermitente evolução do processo industrial, o próprio processo de globalização e o advento do consumismo. Todos esses aspectos têm acarretado danos praticamente irreparáveis para o ecossistema mundial, tais como o comprometimento da biodiversidade, a extinção de espécies, mudanças climáticas com o consequente aumento do efeito estufa, a degradação do meio ambiente e do solo, a exploração, o exaurimento ou mesmo o uso indiscriminado dos recursos naturais, dentre tantos outros.

Nós já consumimos 1.5 vezes a capacidade dos nossos recursos, levando-nos para um futuro insustentável que ameaça nosso meio ambiente e nossa própria existência. Se quisermos salvar o planeta devemos reduzir o consumo. Se nós apoiamos os direitos humanos e a boa prática ambiental, nós devemos nos assegurar que qualquer novo produto que compramos é orgânico, respeita uma economia equitativa e tenha sido produzido de forma sustentável. ${ }^{4}$ (tradução livre) (MINNEY, 2006, p.11)

Em nome do crescimento econômico, sacrificam-se o meio ambiente e a dignidade de boa parte da sociedade e, dessa forma, a viabilidade futura da vida humana. (BERLYN, 2012, p. 17) Cria-se, portanto, um dilema: como continuar assegurando o crescimento econômico, do qual somos todos financeiramente dependentes, com o desenvolvimento sustentável, que é imprescindível para a continuidade da perpetuação da vida humana na terra?

Protegidos pelo paradigma do crescimento econômico e todos os seus "benefícios", "nas últimas três décadas, um terço dos recursos naturais do planeta já foram consumidos" (FOX, PRIGGEN, 2007), ou seja, estamos consumindo os recursos naturais em uma velocidade muito maior do que eles mesmos conseguem se regenerar. "Além disso, produzimos resíduos e poluição em um ritmo mais rápido do que aquele necessário para a natureza absorvê-los" (SALCEDO, 2014. p. 17).

Nos Estados Unidos, nos restam menos de $4 \%$ de nossas florestas originais. $40 \%$ das águas não são potáveis. (...) Nós temos 5\% da população mundial, mas estamos consumindo $30 \%$ dos recursos mundiais e criando $30 \%$ do lixo mundial. Se todo mundo consumisse ao nível dos Estados Unidos, precisaríamos de 3 a 5 planetas. E quer saber? Nós só temos um. (FOX, PRIGGEN, 2007)

\footnotetext{
4 "We are already consuming 1.5 times our planet's resources, hurtling towards an unsustainable future which threatens our environment and our very existence If we are to save the planet, we must reduce consumption. If we are to support human rights and sound environmental practice, we must make sure that any new products we do buy are organic, Fair Trade and sustainably produced."
}

Rev. de Direito, Economia e Desenvolvimento Sustentável| e-ISSN: 2526-0057| Porto Alegre | v. 4 | n. 2 | p. 1 - 16 | Jul/Dez. 
Para que seja possível interromper este ciclo e evitar um colapso, a mudança de paradigma é urgente. Há que se intervir na cadeia produtiva e consumerista como um todo, repensar, readequar, reconfigurar, reestruturar, recriar. Além disso, pouco ou quase nada nos vale se a troca de paradigmas for parcial, ela deve ser feita em todas as etapas, ou seja, precisamos de uma verdadeira mudança sistêmica.

Em nosso caso, o sistema da indústria da moda - como vinculada a todas as outras e reconhece que, para alcançar a sustentabilidade continuada, todo o ciclo da moda deve passar por melhorias, não só algumas de suas fases. (...) A mentalidade sustentável baseia-se em reciprocidade e complexidade, e em uma profunda compreensão dos padrões, das redes, dos equilíbrios e dos ciclos em jogo no sistema da moda. (...) precisamos ainda focar no aqui e agora e tomar decisões pragmáticas e práticas sobre, por exemplo, a escolha de fibras têxteis, fabricantes e acabamentos de tecido. Para chegar a um ponto em que isso aconteça simultaneamente, precisamos desenvolver conhecimento aplicado, ou sabedoria prática. Aristóteles descreveu-a como 'combinação de vontade moral e habilidade moral'; isto é, uma fusão de experiência adquirida com o tempo, conhecimento dos sistemas em vigor e grande capacidade de improvisação. (FLETCHER, GROSE, 2011, p 11)

Diante da urgência dessa mudança sistêmica, como proposto, iremos analisar a primeira etapa do ciclo da vida das roupas, ou seja, a produção de algodão e impactos da fibra natural mais utilizada do mundo como matéria prima para a confecção de roupas, o algodão.

\section{O IMPACTO DA COTONICULTURA NO MEIO AMBIENTE}

Juntas, as indústrias da moda, da construção civil e de alimentos formam o triunvirato das maiores indústrias globais. Estima-se que uma a cada seis pessoas no mundo está direta ou indiretamente vinculada ao mundo da moda ${ }^{5}$, fazendo dela a indústria mais dependente de trabalho da Terra. A moda está implicada nos sistemas mais amplos de controle e poder da era moderna (FLETCHER, 2014, p. 142).

As roupas, tecidos e indústrias de apoio associadas empregam um sexto da população mundial, desde o cultivo de algodão até a peça finalizada. Por isso,

\footnotetext{
${ }^{5}$ As profissões relacionadas à moda vão das mais óbvias às mais distantes, como: agricultor, produtor, empresário, costureira, bordadeira, rendeira, tricoteira, estilista, designer, gestor de recursos humanos, técnicos das mais diversas áreas, secretária, recepcionista, fotógrafo, produtor, modelo, editor, roteirista, publicitário, motorista, contador, vendedor, varejista, alfaiate, desenhista, projetista, modelista, dentre outras tantas.
}

Rev. de Direito, Economia e Desenvolvimento Sustentável| e-ISSN: 2526-0057| Porto Alegre | v. 4 | n. 2 | p. 1 -16 | Jul/Dez. 
se você pensou que a moda não estava salvando bebês, pense novamente: ela tem o poder de mudar o mundo. ${ }^{6}$

Proporcionalmente importante à indústria da moda é a produção de algodão (cotonicultura), que, ao lado da produção de poliéster, são as fibras de maior consumo no mundo, mas "enquanto fibra natural, ela é unanimidade global” (BERLYN, 2012, p. 35). Isto porque o "algodão é produzido em 100 países e usa aproximadamente 2,5\% das propriedades agrícolas do mundo" (MELCHETT In: MINNEY, 2006, p. 40), além disso, “aproximadamente 100 milhões de agricultores, a maioria nos países mais pobres do mundo, são dependentes da plantação do algodão" (MELCHETT In: MINNEY, 2006, p. 40).

Mas a que se deve o aumento da produção de algodão das últimas décadas? Enquanto nosso consumo e desejo por moda aumenta, o próprio algodoeiro está se recriando para acompanhar essa evolução.

Tem havido este grande movimento em direção à industrialização da agricultura, à intensificação da agricultura. Então, ao invés dos métodos tradicionais de cultivo, que eram sincronizados com a natureza, eram ligados aos ciclos do ano normal e às estações, o que vemos agora é uma intensificação onde a terra é quase reconsiderada como se fosse uma fábrica. (MORGAN, 2015)

Segundo dados da Associação Brasileira dos Produtores de Algodão - ABRAPA (ASSOCIAÇÃO BRASILEIRA DE PRODUTORES DE ALGODÃO - ABRAPA, 2016), a demanda mundial tem aumentado gradativamente desde a década de 1950, dados anuais indicam um crescimento médio de 2\%; além disso, uma média de 35 milhões de hectares de algodão é plantada a cada ano em todo o planeta; o comércio mundial de algodão movimenta cerca de US\$ 12 bilhões e envolve mais de 350 milhões de pessoas em sua produção, desde as fazendas até o processamento e embalagem. Atualmente, os principais países produtores da fibra são a China, a Índia, Estados Unidos, Paquistão e o Brasil.

Para que fosse possível acompanhar a demanda mundial por matéria-prima, o cultivo de algodão, assim como toda sua cadeia produtiva, teve que se reinventar. Percebendo essa necessidade, a Monsanto ${ }^{7}$, empresa multinacional de agricultura e biotecnologia, investiu suas pesquisas para modificar geneticamente as sementes de inúmeras plantas, dentre elas, a do

\footnotetext{
6 "Why fashion? The clothing textiles and associated support industries employ one-six of the world's population, from growing cotton crops to finishing garments. so if you thought fashion was not saving babies, think again: it has the power to chance the world." BROWN, 2013, p. 11.

${ }^{7}$ MONSANTO. Para mais informações, acessar: http://www.monsanto.com/pages/default.aspx .
} 


\section{A INDÚSTRIA DA MODA EM CONFLITO: O PARADIGMA DO CRESCIMENTO ECONÔMICO VERSUS O PARADIGMA DA SUSTENTABILIDADE}

algodão $^{8}$. A priori essas mudanças deveriam trazer resistência às plantas contra pestes e má formações, duplicar a produtividade, fazer com que fossem mais resistentes e necessitassem de uma menor quantidade de agrotóxicos e pesticidas. Ocorre que, para que isso fosse possível, a empresa monopolizou a comercialização dessas sementes, e, juntamente com as empresas Cargill, Nestlé e Wal-Mart, dominou as cadeias de suprimento de alimentos e produtos agrícolas - desde as sementes até as prateleiras dos supermercados. Esses dados foram apontados em 2005 em um relatório apresentado pela Action Aid (POWER HUNGRY SIX REASONS TO REGULATE GLOBAL FOOD CORPORATIONS, 2005). Além disso, alguns estudos $^{9}$ indicaram que os produtos transgênicos da Monsanto não apenas poderiam provocar doenças, tais como infecções e cânceres, em agricultores ou pessoas que tiveram contato com o produto por via direta ou indireta, como, também destruir o ecossistema nativo.

A partir da modificação genética, conhecida como transgenia, a Monsanto não apenas tinha o monopólio da produção e venda das sementes modificadas, como também, produzia e vendia os agrotóxicos e pesticidas que eram vitais para a perseverança da safra. Esses venenos não eram mais aplicados de forma ocasional, como antigamente, em cada planta que apresentava erva daninha, mas demandava a necessidade de que fossem aplicados de forma pulverizada nos campos inteiros de plantação, ou seja, tanto nas plantas saudáveis quanto nas plantas doentes, sobrecarregando, com sua aplicação e resíduos, tanto a plantação, como o solo, os microrganismos, os lençóis freáticos, o ar, a biodiversidade e toda a população que vive em torno das áreas de plantação de algodão, sem contar, ainda, o considerável aumento de emissão dos efluentes ${ }^{10}$.

Vandana Shiva, ativista ambiental e autora de importantes obras ${ }^{11}$ que relatam sua expediência com o meio-ambiente, justiça, sustentabilidade e globalização, explica que, na Índia:

\footnotetext{
${ }^{8}$ Trabalhos científicos bem aceitos, indicam que a variedade de algodão GM mais adequada para a redução do uso de substâncias químicas é a Bt. O algodão Bt foi projetado de modo que o código genético da planta incluísse uma toxina bacteriana (Bacillus thuringiensis, de onde "Bt") venenosa para as pragas; isso significa que o cultivo é atacado com menos frequência e, portanto, requer menos aplicações de pesticidas. FLETCHER, GROSE, 2011, p 23.

9 TRANSGÊNICOS CAUSAM ATÉ TRÊS VEZES MAIS CÂNCER EM RATOS, DIZ ESTUdO. Disponível em: http://noticias.uol.com.br/ciencia/ultimas-noticias/redacao/2012/09/19/transgenicos-matam-maiscedo-e-causam-ate-tres-vezes-mais-cancer-em-ratos-diz-estudo.htm. Acesso em agosto de 2016.

${ }^{10}$ A água é um dos principais recursos que vêm sendo explorados de maneira imprópria pelo setor têxtil. Em especial na irrigação de plantações de algodão, mas também nos setores de acabamentos e beneficiamentos têxteis. (...) Todos os resíduos líquidos ou gasosos produzidos por indústrias ou por esgotos domésticos urbanos lançados no meio ambiente são chamados de efluentes. BERLYN, 2012, p. 38.

${ }^{11}$ Para mais referencias da autora ver: SHIVA, Vandana. Las Nuevas Guressas de la Globalización: semillas, agua y formas de vida. Traducción: Néstor Cabrera. Madrid: Editorial Popular, 2007.
}

Rev. de Direito, Economia e Desenvolvimento Sustentável| e-ISSN: 2526-0057| Porto Alegre | v. 4 | n. 2 | p. 1 - 16 | Jul/Dez. 
$\mathrm{O}$ algodão Bt é um algodão no qual o gene foi adicionado de uma bactéria, para produzir uma toxina. Mas o algodão $\mathrm{Bt}$, que deve controlar uma peste, foi oferecido porque é uma forma das empresas possuírem a semente. Ao patentear essas plantas geneticamente modificadas, a Monsanto tornou-se a maior corporação de sementes e de químicos da história. (...) Então os fazendeiros se endividam quando compram as sementes, por causa do alto custo, $17.000 \%$ a mais do que as sementes comuns. Eles adquirem altas dívidas porque a promessa de controle das pestes não é cumprida, então eles têm que comprar mais pesticidas. A tragédia com os produtos químicos, sejam fertilizantes ou pesticidas, é que eles são o que se chama de narcóticos ecológicos: quanto mais você os usa, mais precisa usá-los. Por um tempo, a produção de um único produto aumenta e depois ele começa a diminuir, porque se contaminou o solo. (...) As empresas que fazem as sementes geneticamente modificadas e os químicos são as mesmas empresas. E são as mesmas que fazem os remédios que estão patenteando agora. Então, se você tem câncer, eles têm mais lucro, para eles é ganhar, ganhar, ganhar e ganhar. Já para a natureza e para as pessoas é perder, perder, perder e perder. E chega o momento que esses agentes dessas empresas chegam para o fazendeiro e dizem: 'você me deve este tanto, você não me pagou, agora tua terra é minha terra'. Neste dia o fazendeiro vai até sua plantação toma uma garrafa de pesticida, e morre. (MORGAN, 2015)

Quem paga o alto custo dessa industrialização da agricultura, além do meio ambiente, é o próprio agricultor, sua família e a comunidade onde vive. Com tanto foco nos impactos ambientais da cotonicultura, é dada pouca atenção para os efeitos na população humana (STYLES. 2014. p. 15). De acordo com as estatísticas do próprio governo indiano (STYLES. 2014. p. 15), estima-se que, na Índia, mil produtores rurais cometem suicídio a cada mês, em decorrência da pressão das grandes empresas para que efetuem o pagamento das dívidas. Nos últimos 16 anos, já existiram mais de 250 mil registros de suicídios de fazendeiros na Índia, é quase um fazendeiro a cada 30 minutos (MORGAN, 2015).

Não obstante os dados surpreendentes de suicídio, os efeitos dos agrotóxicos pulverizados nas plantações, seus resíduos deixados no solo, seu alto teor de toxicidade e seu despejo de forma negligente nos rios e afluentes, contaminando toda população que vive em torno e depende deles para subsistência tem chamado atenção para realidades alarmantes: "as plantações de algodão (...) são responsáveis por $16 \%$ do consumo total de inseticidas no mundo. Apenas uma gota de aldicarbe, quando absorvida pela pele, pode ser suficiente para matar um

. Las victorias de una india contra el expolio de la biodiversidad. Traducción: Pascual Ayet Cubero. Agricultura ecológica la Fertilidad de la Terra. 2012.

Manifesto para uma Democracia de la Terra: Justicia, Sostentabilidad y paz. Traducción: Albino Santos Mosquera. Barcelona: Piadós Estado y Sociedad 144, 2006.

Rev. de Direito, Economia e Desenvolvimento Sustentável| e-ISSN: 2526-0057| Porto Alegre | v. 4 | n. 2 | p. 1 - 16 | Jul/Dez. 
homem adulto." ${ }^{12}$ Além disso, doenças graves, tais como retardo mental, câncer, debilidades e deficiências físicas, têm sido recorrentes dos vilarejos indianos, principalmente nas crianças.

\begin{abstract}
A maioria do algodão da Índia é cultivado na região de Punjab, (...). O Dr. Pritpal Singh tem estudado os efeitos desses químicos na saúde humana e seus relatórios mostram o aumento dramático no número de defeitos congênitos, cânceres e doenças mentais aqui na região. 'Você pode ir a cada povoado e você verá inúmeras pessoas sofrendo de câncer. 70 a 80 crianças em cada povoado estão sofrendo de retardo mental severo e deficiências físicas. As empresas de fertilizantes e pesticidas negam completamente os efeitos secundários de seus produtos, e esses são os sintomas clássicos da toxicidade deles. Em um povoado, existem 60 crianças com retardo mental (...), então é um fenômeno muito perigoso em Punjab. E os pobres, trabalhadores e pequenos fazendeiros chegaram no limite de seus rendimentos e não podem pagar por tratamento. Então, eles aceitam a morte de seus filhos. Essa mãe está esperando a morte de seu filho'. (MORGAN, 2015)
\end{abstract}

Ainda, a produção industrializada dos algodões, ou seja, dos algodões geneticamente modificados (GM), ainda representa a esmagadora maioria da produção de algodão no mundo. Estima-se que a produção de algodão transgênico faça uso de três por cento do consumo mundial de água, e um quilo de fibra de algodão consome 10.000 litros de água (MINNEY, 2006, p. 40). Levando em conta toda a produção mundial, esses números são alarmantes.

Diante dessa realidade, não há como ignorar a urgência de uma mudança sistêmica no mundo da moda, principalmente, como analisado até então, na primeira etapa de sua cadeia produtiva. Há que se levar em consideração o impacto ambiental, o social e o econômico ao longo de toda a cadeia produtiva - desde a produção rural até o setor de serviços (MELCHETT, In: MINNEY, 2006, p.40).

\title{
3. POSSIBILIDADES PARA UMA MUDANÇA SISTÊMICA
}

Vestimos plantas, peles de bichos, saliva de lagartas e petróleo (BERLYN, 2012, p. 25), ou seja, é a natureza que provém todos os recursos que precisamos para fomentar essa indústria criada pelo homem da qual todos nós usufruímos, a indústria da moda. Sendo assim, nada mais justo do que a sociedade como um todo não meça esforços para encontrar um

12 Para ter acesso a esse relatório ver: The deadly chemicals in cotton. ENVIRONMENTAL JUSTICE FOUNDATION. Report, 2007. Disponível em: http://www.ejfoundation.org. Acesso em agosto de 2016.

Rev. de Direito, Economia e Desenvolvimento Sustentável| e-ISSN: 2526-0057| Porto Alegre | v. 4 | n. 2 | p. 1 - 16 | Jul/Dez. 
equilíbrio que garanta, de um lado, um meio ambiente em equilíbrio e, do outro, alternativas para viabilizar uma mudança sistêmica em busca da continuidade dessa indústria.

O custo atual desta indústria está sendo alto demais, isto porque, como depreendemos do estudo da primeira parte da cadeia produtiva, os impactos causados até hoje já estão sobrecarregando nosso planeta, nossa sociedade e nossa economia. Os recursos naturais estão sendo usados de forma negligente; a agricultura sofre graves consequências com o fenômeno de sua própria industrialização; o monopólio das empresas que detém a patente de sementes geneticamente modificadas, dos venenos, bem como dos remédios que curam as doenças causadas por eles, faz com que a população que depende economicamente da agricultura para sobreviver se torne hipossuficiente e totalmente dependente dessas empresas; as doenças, a precariedade das condições de vida dos trabalhadores e a busca dos empresários pelo lucro estão levando o atual modelo rumo ao colapso.

Diante dessa realidade, a própria indústria da moda tem um papel fundamental a desempenhar nesta verdadeira revolução e, para Safia Minney ${ }^{13}$, pode fazer isso:

Reduzindo a quantidade de água, de terra e de energia que usa para crescer, produzindo e transportando fibras usadas na confecção das roupas, garantindo que os trabalhadores que fazem essas roupas estão sendo pagos o suficiente para promover seu sustento e garantindo que os trabalhadores estão vivendo em condições que ajudem a desenvolver suas próprias comunidades. (MINNEY, 2006, p.11)

Para ajudar a viabilizar essas mudanças, a autora criou a Organização Mundial do Comércio Equitativo ("World Fair Trade Organization"14) que tem a missão de contribuir com o combate à pobreza, às mudanças climáticas e a crise econômica mundial, para isso instituiu 10 Princípios ${ }^{15}$ básicos a serem observados nas relações comerciais. Segundo a Organização, o

\footnotetext{
13 "Safia Minney é a fundadora da marca "People Tree", pioneira no Comércio Equitativo (Fair Trade), moda e estilo de vida da marca sustentável. Ela desenvolveu a primeira cadeia de suprimentos de vestuário de comércio orgânico e justo e é reconhecida pelo Fórum Econômico Mundial como uma empreendedora social em circulação. Ela iniciou movimento chamado Dia Mundial do Comércio Equitativo (World Fair Trade Day) e Raiva de Pano (Rag Rage), e é membro-fundadora do Fórum Ético Fashion (Ethical Fashion Forum), Revolução da Moda (Fashion Revolution) e Academia Morango da Terra (Strawberry Earth Academy), que promovem o design ecológico. Seu trabalho, pioneiro ao longo de 25 anos, trouxe meios de vida sustentáveis e bem-estar social para mais de 5.000 agricultores economicamente marginalizados, artesãos e alfaiates no mundo em desenvolvimento." (tradução livre) MINNEY, Safia. 2006, p. 8.

${ }^{14}$ WORLD FAIR TRADE ORGANIZATION. Para mais informações, acessar: www.wfto.com.

${ }^{15}$ 1. Criar oportunidades para produtores em desvantagem econômica; 2. Transparência e Prestação de Contas; 3. Práticas de Comércio Equitativo; 4. Pagamentos a preço justo; 5. Assegurando a proibição de trabalho infantil ou trabalho forçado; 6. Comprometimento à não-discriminação, igualdade de gênero e emponderamento econômico
}

Rev. de Direito, Economia e Desenvolvimento Sustentável| e-ISSN: 2526-0057| Porto Alegre | v. 4 | n. 2 | p. 1 - 16 | Jul/Dez. 


\section{A INDÚSTRIA DA MODA EM CONFLITO: O PARADIGMA DO CRESCIMENTO ECONÔMICO VERSUS O PARADIGMA DA SUSTENTABILIDADE}

Banco Mundial informou que mais de um bilhão de pessoas ainda sobrevive com ou menos de U\$1.25 por dia, por isso acredita que o comércio deve beneficiar os mais vulneráveis e desenvolver meios de subsistência sustentáveis desenvolvendo oportunidades para os pequenos fazendeiros e produtores.

Alternativas e ideias sustentáveis surgem todos os dias quer seja na forma de variação de modos de produção da cotonicultura, sejam incentivos e melhores condições da produção local, estratégias de design sustentável, entre várias outras. O direcionamento deste estudo nos permite analisar os cinco principais tipos de algodão de menor impacto.

Hoje, de fato, o algodão orgânico só representa de $0,24 \%$ a $0,74 \%$ da produção mundial de algodão (FLETCHER, GROSE, 2011, p 23). O que qualifica a cotonicultura como orgânica/ecológica/sustentável é a produção em harmonia com os ciclos da natureza, livre de agroquímicos perigosos e sem o uso de sementes geneticamente modificadas. Para que possa ser comercializado como orgânico, o algodão deve receber uma certificação oficial de uma agência independente ${ }^{16}$.

Além do algodão ecológico, existem alternativas como o algodão de comércio justo (fairtrade $)^{17}$ que se caracteriza por decorrerem de produtores de pequenas empresas familiares, organizados em cooperativas ou associações, o preço mínimo de comercialização é garantido e pago diretamente às organizações dos produtores, de igual forma ao orgânico, exige que não sejam usados produtos transgênicos, entre outras questões.

Outra possibilidade é a Better Cotton Initiative ${ }^{18}$ (BCI) que é uma associação multinacional da indústria têxtil que tem como objetivo minimizar os impactos da cotonicultura e fornecer formação para os agricultores, os quais são orientados sobre as melhores práticas para reduzir o volume de agrotóxicos, fazer uso consciente e eficiente da água, com a diferença de que a BCI permite o uso de sementes geneticamente modificadas, desde que observados os princípios específicos da associação.

\footnotetext{
da mulher e a livre associação; 7. Assegurando boas condições de trabalho; 8. Proporcionando capacitação; 9. Promovendo Comércio Equitativo; 10. Respeito pelo meio ambiente. 10 PRINCIPLES OF FAIR TRADE. Disponível em: http://www.wfto.com/fair-trade/10-principles-fair-trade. Acesso em agosto de 2016.

${ }^{16}$ As principais certificações para matéria prima têxteis são: Öki-Tex 100, Öki-Tex 1.000, EU Eco Flower, OE Organic Exchange, Global Recycle Standar e Global Organic Textile Standard. Para mais informações: SALCEDO, 2014. p. 70.

17 FAIRTRADE FOUNDATION. Disponível em: http://www.fairtrade.org.uk/en/buying-fairtrade/cotton. Acesso em agosto de 2016.

${ }^{18}$ BETTER COTTON INITIATIVE. Disponível em: http://bettercotton.org/. Acesso em agosto de 2016.
}

Rev. de Direito, Economia e Desenvolvimento Sustentável| e-ISSN: 2526-0057| Porto Alegre | v. 4 | n. 2 | p. 1 - 16 | Jul/Dez. 
A iniciativa Cotton Made in África ${ }^{19}$ (CmiA), começou a ser desenvolvida pela Fundação Aid by Trade no ano de 2005 com o propósito de ajudar os pequenos agricultores africanos e suas famílias a melhorarem as condições de produção e de vida. Os padrões dessa iniciativa exigem a rotação de cultivos, isso significa que o algodão deve ser produzido alternadamente com outros tipos de sementes, como o milho, a soja, isso permite o enriquecimento natural do solo e reduz a níveis mínimos o surgimento de pragas. Além disso, é vedada tanto a utilização de determinados produtos químicos, bem como a utilização de sementes geneticamente modificadas.

Por fim, o algodão reciclado é

Aquele fabricado a partir dos resíduos de algodão pré- ou pós-consumo. No primeiro caso, trata-se de reciclagem de restos de fios ou tecidos; no segundo da reciclagem de roupas usadas e descartadas. (...) O resultado da reciclagem de algodão são fibras curtas, difíceis de serem fiadas. Por esse motivo, o algodão reciclado é normalmente misturado a fibras virgens, para que o fio se torne resistente ao processo de produção. Quando misturado ao algodão convencional ou ao algodão orgânico, o algodão reciclado pode representar entre $20 \%$ e $30 \%$ da composição de tecidos planos e de até $50 \%$ no caso de tecidos circulares. Se misturado a fibras sintéticas, como o poliéster ou o acrílico, o algodão reciclado pode chegar a compor $80 \%$ do tecido. (SALCEDO, 2014. p. 63)

Tendo em vista, como afirma Anthony Giddens, que "a natureza nunca 'fala por si mesma', mas as pessoas falam em nome dela" (GIDDENS, 2012, p. 124), cabe ao ser humano, usufrutuários dela, observar e interpretar o que ela tem a dizer. A finitude dos recursos naturais, a exaustão e a sobrecarga do solo, a industrialização da agricultura, os impactos sociais e as discrepâncias econômicas entre produtores e empresários, é gritante, sendo assim, torna inevitável uma proposta de mudança sistêmica. Para que isso aconteça precisamos falar pela natureza e encontrar formas diferentes de plantar, colher e produzir, assim como, precisamos encontrar formas diferentes de consumir.

Muitos problemas ambientais e sociais na indústria da moda não têm solução puramente técnica ou mercadológica: ao contrário, são morais e éticas (...) e para isso precisamos tomar distância do modo convencional de fazer negócio e examinar o que define, dirige e motiva os sistemas maiores. (FLETCHER, 2011, p. 75)

${ }^{19}$ COTTON MADE IN AFRICA. Disponível em: http://www.cottonmadeinafrica.org/en/. Acesso em agosto de 2016.

Rev. de Direito, Economia e Desenvolvimento Sustentável| e-ISSN: 2526-0057| Porto Alegre | v. 4 | n. 2 | p. 1 - 16 | Jul/Dez. 


\section{A INDÚSTRIA DA MODA EM CONFLITO: O PARADIGMA DO CRESCIMENTO ECONÔMICO VERSUS O PARADIGMA DA SUSTENTABILIDADE}

Encontrar alternativas à sistemática contemporânea não é mais uma escolha, é uma imposição ética e moral com nosso próprio planeta, diante disso, frequentemente surgem novas propostas que desaceleram, que reutilizam, que transformam tanto a matéria-prima, como as peças por elas produzidas. Exemplos como Moda Ética ${ }^{20}$, Ecomoda $^{21}$, Slow Fashion ${ }^{22}$, o uso de algodão orgânico, formas mais ecológicas e conscientes de produção, uso de corantes naturais, tingimento com uso reduzido de substâncias químicas, desperdício mínimo ou total aproveitamento no corte e na costura da peça, reciclagem da peça final para transformá-la em uma nova peça, design de peças versáteis, transazonalidade ${ }^{23}$, real valorização e remuneração justa para o produtor e todos trabalhadores da cadeia produtiva, interrupção do ciclo do consumismo, peças cada vez menos industrializadas e cada vez mais artesanais, participação de ONGs na organização de produções locais, redução do uso de água na produção e manutenção das peças, dentre tantas outras propostas inovadora.

A moda está implicada nos sistemas mais amplos de controle e poder da era moderna (FLETCHER, 2014) e justamente por estar tão próxima de cada um de nós é que temos o poder de impor mudanças consideráveis, antes que seja tarde demais.

\footnotetext{
${ }^{20}$ Moda ética: vestuário que é manufaturado de acordo com os direitos humanos e os de trabalho determinados pela Organização Internacional do Trabalho. GWILT, 2014, p. 161

${ }^{21}$ Ecomoda: a ecomoda (moda ecológica, moda bio ou moda orgânica) engloba todas aquelas peças de roupa e outros produtos de moda feitos por métodos menos prejudiciais ao meio ambiente. Esse termo enfatiza, portanto, a redução do impacto ambiental. SALCEDO, 2014. p. 32.

${ }^{22}$ Slow Fashion (moda lenta): não é o contrário de fast-fashion (moda rápida). Não há, aqui, nenhuma dualidade, Trata-se apenas de um enfoque diferente, segundo o qual estilistas, compradores, distribuidores e consumidores estão mais conscientes do impacto das roupas sobre pessoas e ecossistemas. (...) a slow fashion enxerga o consumidor e seus hábitos como parte importante da cadeia. Ao contrário do que se poderia pensar, a moda lenta não é um conceito baseado no tempo, e sim na qualidade, que no fim, evidentemente, tem alguma relação com o tempo dedicado ao produto. SALCEDO, 2014. p. 33.

${ }^{23}$ Transazonalidade: a moda prospera com a mudança e a velocidade, e com a rotatividade das peças no guardaroupa de um indivíduo. Para garantir a renovação do estoque e compras adicionais, a indústria da moda fabricou 'temporadas' artificiais de varejo que requerem novos visuais e estilos. A participação nessas temporadas criadas pelo homem denota um código social, uma sensação de ser bem-sucedido, de ser capaz de estar a par das últimas tendências e de ter dinheiro para compras frequentes: 'volta às aulas', 'renovação', 'viagens' e 'férias' são algumas das chamadas para atrair os consumidores a shooping centers, todas idealizadas para incitar trocas de guardaroupas e garantir o fluxo contínuo de produtos pelo sistema industrial da moda. As peças transazonais podem deter essa lógica dominante da indústria. Em vez de adotar novos modelos e palhetas de cores que duram semanas, os designers identificam cores que tendem a funcionar em diferentes estações e combinações de guarda-roupas. FLETCHER, GROSE, 2011, p. 79.
}

Rev. de Direito, Economia e Desenvolvimento Sustentável| e-ISSN: 2526-0057| Porto Alegre | v. 4 | n. 2 | p. 1 - 16 | Jul/Dez. 


\section{CONSIDERAÇÕES FINAIS}

No atual estágio do capitalismo, na busca pela acumulação de capital, as empresas transnacionais ainda dependem da existência de mercados nacionais e do Estado, além de demonstrarem fraquezas que podem ser exploradas pelos grupos-ambientalistas, consumidores e sindicatos, provocando alterações significativas de seus comportamentos.

Essa ação dos grupos, objetivando redefinir mercados, faz emergir novos padrões culturais. Dessa forma, sensibilidades culturais sobre a qualidade da nutrição e a proteção ao meio ambiente indicam que um discurso alternativo está se caracterizando. (BONANO, MARSDEN, GRAZIANO DA SILVA, In: CAVALCANTI, 1999, p. 351)

No entanto, Aguilera Klink (AGUILERA KLINK, In: DUBOIS, 2000, p. 115) destaca que ainda há a necessidade de aprofundar as implicações ambientais dos estilos de vida. Fundamentalmente é um aspecto cultural, pois refletem pautas culturalmente aprendidas e não questionadas de pensamento e comportamento. Devemos reconhecer que os problemas ambientais assim como os conflitos sociais, refletem um conflito intra e intergeracional de caráter multidimensional. Ou seja, a deterioração ambiental e a defesa do meio ambiente impõem custos e geram benefícios, tanto monetários como não monetários (sobre a saúde, os ecossistemas, as propriedades, etc.) que recaem sobre diferentes pessoas e grupos em diferentes momentos do tempo, pelo fato que muitos efeitos demoram anos a aparecer.

David Pearce (PEARCE, 2004) e René Passet (PASSET, 2002) entendem que devemos garantir o desenvolvimento da esfera produtiva em interdependência com o conjunto de seus ambientes - humano e natural - sem reduzi-los a uma pura lógica mercantil.

Concordando com Kahil (KAHIL, 2005, p. 7201) sugere-se que, a despeito do modelo econômico dominante, é do reconhecimento do território de uso comum a todos e da confluência de novas técnicas que será possível uma resistência, uma construção de homens fortes que buscam cidadania plena sustentada numa outra globalização. 


\section{REFERÊNCIAS BIBLIOGRÁFICAS}

ASSOCIAÇÃo BRASILEIRA DE PRODUTORES DE ALGOdÃo - ABRAPA. Disponível em: http://www.abrapa.com.br/estatisticas/Paginas/Algodao-no-Mundo.aspx.

BERLYN, Lilian. Moda e sustentabilidade: uma reflexão necessária. São Paulo: Estação das Letras e Cores, 2012.

BETTER COTTON INITIATIVE. Disponível em: http://bettercotton.org/.

BROWN, Sass. Refashioned: cutting-edge clotthing from upcycled materials. London: Laurence King Publishing Ltd, 2013.

CAVAlCANTI, Josefa Salete Barbosa. (Org), Globalização, Trabalho e Meio Ambiente. Recife: Editora, UFPE, 1999.

CONFERÊNCIA DAS NAÇÕES UNIDAS PARA O MEIO AMBIENTE HUMANO. Disponível em: http://www.direitoshumanos.usp.br/index.php/Meio-Ambiente/declaracao-deestocolmo-sobre-o-ambiente-humano.html.

COTTON MADE IN AFRICA. Disponível em: http://www.cottonmadeinafrica.org/en/.

DUBOIS, Afonso. MILLÁN, Juan Luiz, ROCA, Jordi. (Coords.). Capitalismo, Desigualdades Y Degradación Ambiental. Barcelona: Icaria editorial, 2000.

ENVIRONMENTAL JUSTICE FOUNDATION. Report, 2007. Disponível em: http://www.ejfoundation.org.

FAIRTRADE FOUNDATION. Disponível em: http://www.fairtrade.org.uk/en/buyingfairtrade/cotton.

FLETCHER, Kate. Sustainable fashion and textiles: design journeys. London: Earth from Routledge, Second Edition, 2014.

FLETCHER, Kate. GROSE, Lynda. Moda e Sustentabilidade: design para a mudança. Tradução Janaína Marcoantonio. São Paulo: Editora Senac, 2011.

KAHIL. Samira Peduti. Usos do Território: uma questão política. In: Anais do X Encontro de Geógrafos da América Latina - 20 a 26 de março de 2005 - Universidade de São Paulo. São Paulo: Universidade de São Paulo, 2005.

LIPOVETSKY, Gilles. O Império do Efêmero: a moda e seu destino nas sociedades modernas. Tradução: Maria Lúcia Machado. São Paulo: Companhia das Letras, 2009.

MINNEY, Safia. Slow Fashion: aesthetics meets ethics. London: New Internationalist, 2006.

MONSANTO. http://www.monsanto.com/pages/default.aspx.

PASSET, René A ilusão neoliberal. Rio de Janeiro: Record, 2002.

PASSO, Priscilla apud BERLYN, Lilian. Moda e Sustentabilidade: uma reflexão necessária. São Paulo: Estação das Letras e Cores, 2012.

PEARCE, David. El crecimiento y el medio ambiente: ¿objetivos compatibles?. Environment matters, 2004. The World Bank Group.

POLLINI, Denise. Breve História da Moda. Editora Claridade, São Paulo, 2007.

Rev. de Direito, Economia e Desenvolvimento Sustentável| e-ISSN: 2526-0057| Porto Alegre | v. 4 | n. 2 | p. 1 - 16 | Jul/Dez. 
POWER HUNGRY SIX REASONS TO REGULATE GLOBAL FOOD CORPORATIONS. ActionAid International, 2005. Disponível em: https://www.actionaid.org.uk/sites/default/files/doc_lib/13_1_power_hungry.pdf.

RELATÓRIO BRUNDTLAND. Disponível em: https://ambiente.wordpress.com/2011/03/22/relatrio-brundtland-a-verso-original/.

SALCEDO, Elena. Moda Ética para um futuro sustentável. Tradução: Denis Fracalossi. Barcelona: Editora GG Moda, 2014.

SHIVA, Vandana. Las Nuevas Guressas de la Globalización: semillas, agua y formas de vida. Traducción: Néstor Cabrera. Madrid: Editorial Popular, 2007.

Las victorias de una india contra el expolio de la biodiversidad. Traducción: Pascual Ayet Cubero. Agricultura ecológica la Fertilidad de la Terra. 2012.

Manifesto para uma Democracia de la Terra: Justicia, Sostentabilidad y paz. Traducción: Albino Santos Mosquera. Barcelona: Piadós Estado y Sociedad 144, 2006.

STYLES. Ruth. Ecologist guide to fashion. London: Leaping Hare Press, 2014. p. 15.

THE HISTORY OF STUFF. FOX, Louis. PRIGGEN, Erica. Free Range Studios. 2007, Disponível em: http://storyofstuff.org/movies/story-of-stuff/.

THE TRUE COST. Direction: Andrew Morgan. Producer: Michael Ross. Documentary. 2015. Online on http://netflix.com.

TRANSGÊNICOS CAUSAM ATÉ TRÊS VEZES MAIS CÂNCER EM RATOS, DIZ ESTUDO. Disponível em: http://noticias.uol.com.br/ciencia/ultimasnoticias/redacao/2012/09/19/transgenicos-matam-mais-cedo-e-causam-ate-tres-vezes-maiscancer-em-ratos-diz-estudo.htm.

WORLD FAIR TRADE ORGANIZATION. www.wfto.com.

10 PRINCIPLES OF FAIR TRADE. Disponível em: http://www.wfto.com/fair-trade/10principles-fair-trade. 